\title{
Water Quality Assessment Using Remote Sensing and GIS for In-shore Marine Environment Suitability
}

\author{
Ruslisan, Nur H. Kalam, Aglis C. Dwininta, Muhammad H. Habibi, Ernawati T. Rahayu, \\ Nurkhovia Dewi, Eleonora E. Henny K., and Wirastuti Widyatmanti \\ Department of Geographic Information Science, \\ Faculty of Geography, Gadjah Mada University, Yogyakarta, Indonesia \\ Email :widyatmanti@gmail.com
}

\begin{abstract}
Ruslisan, Nur H. Kalam, Aglis C.Dwinita, Muhammad H. Habibi, Ernawati T. Rahayu, Nurkhovia Dewi, Eleonora E. Henny K., and Wirastuti Widyamanti. 2016. Water Quality Assesment Using Remote Sensing and GIS for In-shore Marine Environment Suitability. Aquaculture Indonesiana, 17 (2): 46-53. In-shore marine environment and its adjoining estuary has a potential susceptibility to water pollution due to the continuous discharge of its unhealthy catchment. Seawater quality studies commonly require a very detailed water sampling and analysis, leading to high expenditures on time and energy. This study aims to examine the water quality of the Dodokan Estuary using remote sensing and geographic information system (GIS) approaches, and to determine the most appropriate water environment mapping unit for marine environment suitability studies. Landsat 8 and QuickBird® were used to extract water quality parameters using related spectral transformations. Field surveys were conducted concurrently to the Landsat 8 acquisition time on the study area, to collect water samples for laboratory analysis including sea surface temperature (SST), chlorophylla, Dissolved Oxygen (DO), and Total Suspended Solid (TSS). Mapping units were generated based on visual interpretation on QuickBird ${ }^{\circledR}$ for estuarine plumes, to identify the possible distribution of suspended material from its catchment. The statistical analyses present that the parameter extracted from the satellite imagery and from laboratory analysis produces $\mathrm{R}$ values of 0.7 in average, despite its low value on chlorophyll-a. By utilizing assorted sea-water marine suitability criteria, it can be concluded that the inshore marine environment in the Dodokan Estuary and its surrounding area are suitable for various biota conservation e.g. coral, sea-grass, and mangrove, and in contrast, marine aquaculture. The knowledgeable uses of remote sensing and GIS also assist the sea-water qualities assessment mapping in term of providing boarder understanding of a water environment condition to effectively minimize the cost of sampling.
\end{abstract}

Keywords: Catchment; In-shore marine; Remote sensing and GIS; Suitability; Water quality; Water sampling

\section{Introduction}

The natural resources on both coastal and marine environments in Indonesia consist of many biophysical elements including fishes, coral, seagrass and mangrove, which are well considered to the worldwide biodiversity contribution (Hofmann et al., 2014). The nurturing environments of mangrove fringes which exist along the unimaginable coastline, provide an abundant source of nutrition for the fishes breeding and the growth of inshore marine vegetation (May and Takeda, 2015). One of the element that preserve those nurturing environment is water quality, including sea-water quality which is one of crucial elements in the coastal environment. This water quality is sensitively influenced by physical and chemical conditions of the coastal environment including human activities (Boyd, 2015). In fact, human activities contribute most in sea-water contamination compared to other variables (sedimentation and current) especially through the environments neighboring an estuary. Estuary is an environment where water from the upper catchment discharge to the sea (Bird and Ongkosongo, 2000). This discharge designates the health level of a catchment based on its continuous supply and water quality (Quinn, 2014).

A continuous research on sea-water quality monitoring has to be conducted to support sustainable mari- and aqua-culture. However, the vast in-shore marine area and detailed water sampling needed in this type of research become limitation in applying rapid water quality assesment in applying rapid water quality assessment. Regarding to this matter, a scientific study to provide a robust method to solve those constraints is urgently required. The well-recognised method to support the rapid assessment and to map some parameters of sea-water environment are remote sensing and Geographic Information System (GIS) 
approaches. Recently, there have been more studies that apply remote sensing spectral transformation to extract the water-quality parameters, such as temperature, chlorophyll, total suspended solid (TSS), salinity, or even oil spills identification (Rimmer et al., 2007).

The development of remote sensing and GIS technologies which also have been commonly used to support studies in managing coastal and in-shore marine environment, can become an option to provide a solution for fore mentioned environmental problems (Campbell et al., 2011; Pan et al., 2013). Therefore, this paper aims to examine the uses of remote sensing and GIS approaches for the sea-water quality in Dodokan Estuary and its surrounding in-shore marine environment, by identifying an appropriate mapping unit to reduce the number of sampling, to evaluate the marine environment suitability for various biota conservation areas, and in contras, mari- and aqua-culture.

\section{Material and Method}

\section{Time and site}

In Lombok Province, most of the estuaries, coastal and inshore marine environments have experienced severe pollutions both physic and chemical, due to intensive land-use changes, deforestations and illegal mining explorations in last decade (Putra, 2007). Especially in Dodokan Estuary where this study is conducted (Figure 1), those pollutions have been exaggerated by high sedimentation especially during the rainy season (Putra, 2007).

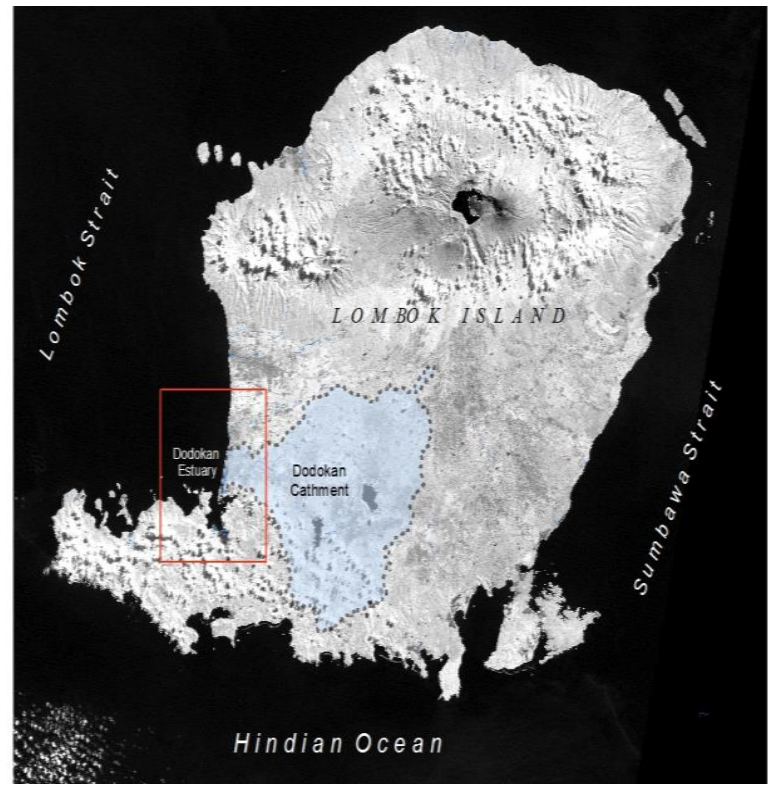

Figure 1. The area of study, Dodokan Estuary
The uplands of this river catchment, Sekotong Hills, was occupied by illegal mining that used mercury to extract gold which unfortunately it was also discharged to the river system (Siswanto et al., 2012; Krisnayani et al., 2012). During field observation in year 2015 and 2016, those mining remained active but their intensity was decreasing. However, the discharge of their wastes to the river still become an apprehension. This situation is worsen by its open estuary characteristics that distributes pollutant and domestic waste along the west coast of Lombok, because of the sea current periodic changing of Lombok straight. Unfortunately, most of the people inhabiting in this coastal area, who are fishermen and farmers, very much utilize this polluted open estuary. As a result, they have been struggling with the degradation of the coastal environment and in-shore marine water quality because it decreases the quality and quantity of their caught fishes and affect their economic income (MFE, 2003). In fact, they have invested a significant amount of money to raise the level of productivity.

\section{Material}

Some instrumens and materials were used in this study to support the satellite image processing, field survey, and result analyses. They were included Landsat 8 imageries, GPS, computer and mapping software (ENVI 4.5, ArcGIS 10.1), refractometer, DO meter, secchi disk, $\mathrm{pH}$ meter and sea-water temperature gauge, and some secondary data: Map of Indonesian Coastal Environment, scale 1:50.000 sheet of Gerung and Map of topography, scale 1:25.000 sheet of Gerung.

\section{Remote sensing image pre-processing}

This study utilizes the Landsat 8 imagery recorded in February 2013, 2014 and 2015. The image time of acuisision was chosen by considering the sedimentation occurences during rainy seasons and the image clarity from the cloud coverages. These multi-temporal imageries were applied to obtain the consistency of their Digital Number (DN-the original value of the recorded image) to identify and preclude the errors of DN. Prior the main image processing for water quality parameter assesment, remote sensing image pre-processing were conducted on those three satellite imageries, using ENVI 4.5 image processing software. It includes radiometric and geometric corrections, which were applying standard remote sensing data processing published by USGS (2015). 


\section{The water quality parameter}

a. Sea Surface Temperature (SST)

SST is one of important physical parameters in determining the water quality level especially that related to the coastal water environment. Water temperature influences the life of marine botany as it is related to the level of DO, marine botany's respiratory systems, and the speed of sea-water self-purification from pollutant (Boyd, 2015). The SST was extracted from a set of algorithms, such as by converting the DN to radian value $(\mathrm{L} \lambda)$ and then to brightness temperature using the algorithm below (USGS, 2015; Chander and Barsi, 2007; Chander et al., 2009):

$$
\begin{aligned}
& \mathrm{L} \lambda=\mathrm{ML}^{*} \mathrm{cal}+\mathrm{AL} \\
& \mathrm{P} \lambda=\mathrm{MP} * \mathrm{Qcal}+\mathrm{AP} \\
& \mathrm{P} \lambda=\frac{p \lambda^{\mathrm{m}}}{\cos \left(\theta_{s z)}\right.}=\frac{p \lambda^{\mathrm{m}}}{\sin \left(\theta_{s e}\right)} \\
& \mathrm{T}=\frac{K 2}{\ln \left(\frac{K 1}{L \lambda}+1\right)}
\end{aligned}
$$

The $\mathrm{K} 1$ and $\mathrm{K} 2$ value are indexes provided in Landsat 8 header. This brightness temperature was converted to the kinetic radiance $\left({ }^{\circ} \mathrm{K}\right)$ using emissivity value of 0.98 that representing the seawater parameter. This Kelvin unit values then were converted to Celcius degree unit.

\section{b. Total Suspended Solid (TSS)}

TSS is particle that is larger than two microns found in the water column (CSIRO, 2003). This physical parameter is a measure of the mass of fine inorganic particles suspended in the water. High concentration of TSS in a water column may become pollutant that influences the quality of sea or estuarine bottoms. This TSS concentration will also reduce light penetration to the water body that cause the decrease of the phosphorus content. Laboratory analyses were conducted to obtain the TSS values.

\section{c. Salinity}

Salinity is amount of salt content in a unit volume of water, measured in part per thousand (ppt). This one of chemical parameters influences the growth of phytoplankton (Hutabarat, 2000). It can also influence the ionic balance of the fish. The salinity level that supports the growth of phytoplankton is around 25-40 ppt with the temperature range of $25-30^{\circ} \mathrm{C}$. In this study, the salinity values were obtained from field measurement and laboratory analysis. d. $\mathrm{pH}$

$\mathrm{pH}$ (potential of Hydrogen) is a measure of acidity or alkalinity of water soluble substance (EPA, 2012; FAO, 2009). pH is commonly measured to understand the sea-water quality condition as a place of environment life (Sabia et al., 2015). A pH value is a number from 1 to 14 , with 6.88 as the middle (neutral) point. This level of acidity influences the sea-water condition and the living organisms within. In this study, the $\mathrm{pH}$ values were also obtained from field measurement and laboratory analysis.

\section{e. Dissolved Oxygen (DO)}

DO is the concentration of dissolved oxygen in the water column that represents the balance between rate at which water equilibrates with the atmosphere, the rate oxygen production by autotrophic growth, and the rate of oxygen consumption by heterotrophic growth (CSIRO, 2003). According Lung (1993), minimum dissolved oxygen used to support fish life is around $4 \mathrm{mg} \mathrm{O} \mathrm{O}_{2} / \mathrm{m}^{3}$. This chemical parameters unit is in $\mathrm{mg} \mathrm{O} \mathrm{O}_{2} / \mathrm{m}^{3}$, or amount of oxygen in a meter volume of water. The DO values were obtained from the water sampling analysed in laboratory.

\section{f. Chlorophyll-a}

Chlorophyll-a is one of biological parameters that presents a plant pigment which provide a measurement of the plants biomass. It is measured based on the suspended biomass of single-celled microscopic plants in $\mathrm{mg} \mathrm{chl} / \mathrm{m}^{3}$, or amount of chlorophyll in a meter volume of water. In this study Chlorophyll-a value was obtained from remote sensing data processing and laboratory analysis. This study also involved visual interpretation on Landsat 8 imagery to support the analysis of the relationship between Chl-a and TSS, in Dodokan Estuary in-shore marine environment. The extraction of the Chl-a values were derived from Landsat 8 using algorithm published by Kishino (1998). This algorithm utilize band visible $(2,3$ and 4$)$ to differentiate the reflectance value that present different content of Chl-a.

$$
\text { Chla }=0.2818\left(\frac{\mathrm{L} 3+\mathrm{L} 4}{\mathrm{~L} 2}\right)^{3.497}
$$




\section{Water sampling and laboratory analysis}

Water sampling stage applied the stratified random sampling method which were determined based on the mapping unit obtained from the matching overlay of SST, Chl-a maps and visual interpretation of the brightness appearance of the sea-water on the satellite imageries (Figure 2). It applied a multi-transect method to cover all units presented on the analysis maps. The field survey was conducted between $9-10$ a.m., coinciding with the time of Landstat 8 satellite data acquisition. Sea-water was collected from each sample point using water sample bottle and was transported immediately to laboratory. The water samples analyses were conducted in Balai Perikanan Budidaya Laut (Mariculture and Fisheries Agency), Sekotong, West Lombok.

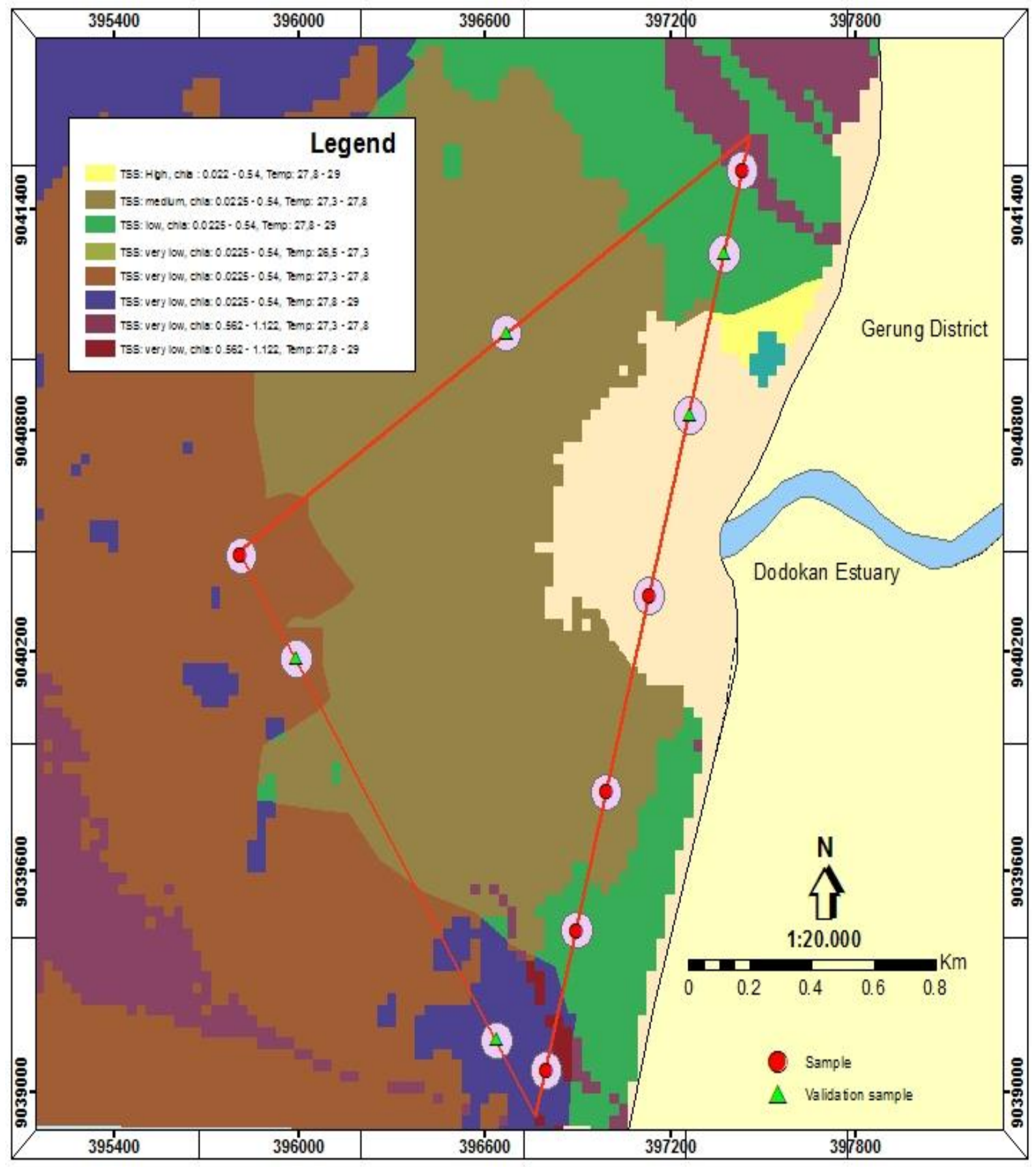

Figure 2. The sampling location based on the mapping units generated by superimposing the water quality parameter spectral tranformations indicated by the pixel square edge shape appearances. 


\section{Statistical analysis}

The laboratory analysis results and field measurement data were synthesized to obtain the information of water-quality characteristics in Dodokan Estuary and its in-shore marine environments. This study was utilizing the Pearson product moments correlation method to observe the correlation between values obtained from satellite imageries and field measurement/labolatory analysis. The acceptable correlation value from the analysis result $(r>0.5)$ underlain the decision to develop models to map each water quality parameter. The final maps presenting the distribution of water-quality parameters were synthesized based on Act No. 51/2004, in regard to the water-quality and suitability for marine biota (Table 1), provided by Ministry of Environment.

Table 1. Criteria of sea-water quality standard for marine biota life suitability (including mari-culture).

\begin{tabular}{|c|c|c|c|}
\hline No. & Parameters & Unit & Standard \\
\hline \multicolumn{4}{|c|}{ Physical parameter } \\
\hline 1. & Temperature & ${ }^{0} \mathrm{C}$ & $28-32$ \\
\hline 2. & TSS & $\mathrm{mg} / \mathrm{L}$ & $<2$ \\
\hline 3. & $\mathrm{pH}$ & - & $7-8.5$ \\
\hline \multicolumn{4}{|c|}{ Chemical parameter } \\
\hline 1. & Salinity & $\%$ & $\begin{array}{l}\text { General: 10-30; } \\
\text { Lamun: } 33-34 ; \\
\text { Coral: } 33-34 ; \\
\text { Mangrove: sd. } 34\end{array}$ \\
\hline 2. & $\mathrm{DO}$ & $\mathrm{mg} / \mathrm{L}$ & $>5,6-9$ \\
\hline 3. & Chlorophyll-a & $\mathrm{sel} / 100 \mathrm{~mL}$ & No algae bloom \\
\hline
\end{tabular}

\section{Result and Discussion}

\section{The validity of water quality maps from Landsat 8 image processing}

The statistical analysis results present a various level of correlation between the values on the image processing analyses and the field measurement/laboratory analyses. The Pearson product moment correlation between those values is 0.78 in average for most of the parameters, indicating a strong correlation between them. Except for Chl-a, the correlation value is only 0.5 , indicating a medium correlation between the values of image analysis and of laboratory analysis. The water condition during the time of sampling and the time of laboratory analysis might become the main justification of this lower correlation value. The regression model then was developed to adjust the values of the image processing analysis based on the field measurements. Subsequently, the interpolation processes were conducted to provide the final maps of each water quality parameter (Figure 3).

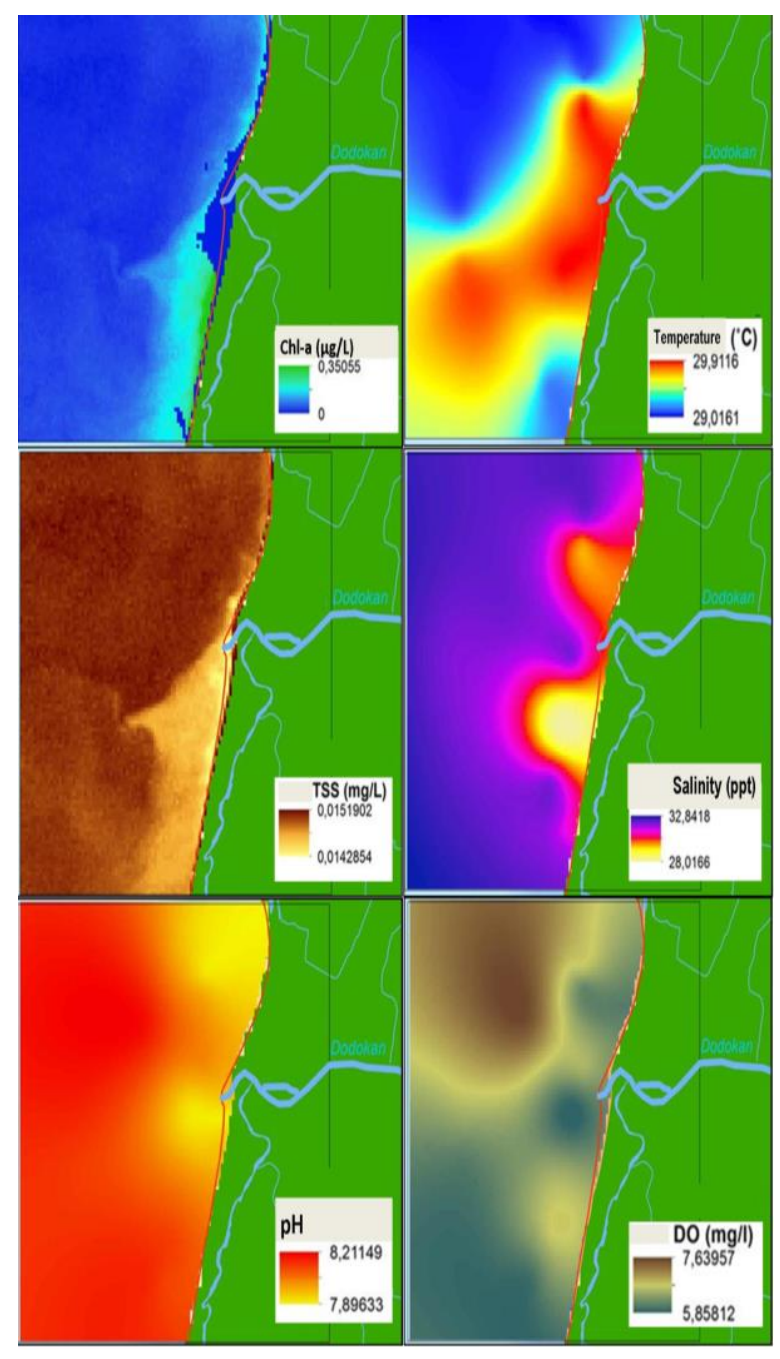

Figure 3. Map of sea-water quality parameters based on spectral, field survey and statistical analyses

The water suitability for in-shore mari-culture and coastal aquaculture

The results of field measurement and laboratory analysis for water quality assessment, which cover SST, salinity, pH, DO and TSS, present that Dodokan Estuary owns various environment characteristics (Table 2). Their water temperatures, as the primary factor which affects the degree of water quality, ranges from $24-30.1^{\circ} \mathrm{C}$. The distribution of high temperatures are mostly situated near to the estuary entrance where are influenced by fresh water discharges. The discharge of river water during rainfall event from the upper catchment, despite during the dry season, contributes warmer water temperature to the seawater environment. The heat of land affects the temperature of river water. Therefore the seawater near the coastline is also warmer compared to the one that is farther. Thus, the farther the inshore marine water from the land is, the lower its temperature is, reaching $24^{\circ} \mathrm{C}$. 
Table 2. The ranges values of sea-water quality parameters

\begin{tabular}{llccc}
\hline No. & \multicolumn{1}{c}{ Parameter } & $\begin{array}{c}\text { Value for sample located } \\
\text { near the estuary entrance }\end{array}$ & $\begin{array}{c}\text { Value for sample located } \\
\text { at further off-shore }\end{array}$ & Range \\
\hline 1. & Temperature & $28-30^{\circ} \mathrm{C}$ & $24-28^{\circ} \mathrm{C}$ & $24-30^{\circ} \mathrm{C}$ \\
2. & Salinity & $28-34 \mathrm{ppt}$ & $30-40 \mathrm{ppt}$ & $28-40 \mathrm{ppt}$ \\
3. & $\mathrm{pH}$ & $7-7.9$ & $7.9-8.2$ & $7-8.2$ \\
4. & Dissolved Oxygen & $5-6 \mathrm{mg} / \mathrm{L}$ & $6-8 \mathrm{mg} / \mathrm{L}$ & $5-8 \mathrm{mg} / \mathrm{L}$ \\
5. & TSS & $0.01-0.2 \mathrm{mg} / \mathrm{L}$ & $0.2-0.6 \mathrm{mg} / \mathrm{L}$ & $0.01-0.06 \mathrm{mg} / \mathrm{L}$ \\
6. & Chlorophyll-a & $0.3-0.8 \mathrm{mg} / \mathrm{L}$ & $0.1-0.3 \mathrm{mg} / \mathrm{L}$ & $0.1-0.8 \mathrm{mg} / \mathrm{L}$
\end{tabular}

Source: field measurement and laboratory analysis (2015)

For salinity parameters, the values are around 28-34 ppt near the entrance and are 30-40 ppt at the in-shore marine environment. The fresh water supply from Dodokan River during the rainy season and sometimes on the dry season, lower the salinity level of the inshore marine water near the estuary entrance. When abundant fresh water discharge occurs during the rainy season, the estuary entrance water environment are classified into brackishwater. These salinity values represent the water zonation in Dodokan estuary which consist of 'low salinity brackishwater', 'brackishwater', and 'sea-water' zones.

The $\mathrm{pH}$ values in the Dodokan estuary and its surrounding in-shore marine are from 7.0 to 8.2. These $\mathrm{pH}$ values are considered suitable for most marine species. The $\mathrm{pH}$ values on the Dodokan upper stream ranges from $6.8-7.5$. It means that the water discharge from the upper catchment doesn't significantly influence the $\mathrm{pH}$ condition of the in-shore marine environment. The DO values range from $5-8 \mathrm{mg} / \mathrm{L}$. These values also indicate that this area is suitable for marine biota habitat since the minimum value is $5 \mathrm{mg} / \mathrm{L}$. If the value of DO is lower that its minimum value, it indicates that the water has severe level of toxicity. The $\mathrm{pH}$ range values from 7-8 shows that this area is categorized into neutral to low alkaline level which is suitable for marine biota. $\mathrm{pH}$ vary directly or indirectly with other water parameters like salinity and temperature, which also influences the dissolved oxygen and ammonia levels. Thus the $\mathrm{pH}$ values become a crucial variable in sea-water quality assessment.

The TSS values are considered low ranging from 0.01 to $0.06 \mathrm{mg} / \mathrm{L}$. The TSS level in the estuary entrance is higher compared to the one that are farther off-shore. Based on the Landsat multi-temporal observation during the dry and rainy season, it is caused by high sediment supply from the upper catchment. This condition is similar to Chl-a, where their high values are also located nearby the entrance, ranging from 0.3 to $0.8 \mathrm{mg} / \mathrm{L}$; whereas, on the farther off-shore, Chl-a values only varies from $0.1-0.3 \mathrm{mg} / \mathrm{L}$. The sediment supply on the estuary entrance with its nutrition from the Dodokan River could possibly influence the development of chlorophyll. Conversely, the value of salinity, $\mathrm{DO}$, and $\mathrm{pH}$, are increasing along with the distance of water sample locations from the coastline and the estuary entrance.

The final map of inshore marine environment suitability for marine biota (Figure 4) shows that generally this area is divided into two classes. The first level of suitability (S1), presented by green area, indicates that those areas are suitable for marine biota habitat. On the contrary, the area near the estuary entrance is classified as unsuitable for marine biota habitat, presented by orange-redish area. This unsuitable area is considered unstable because it experiences high fluctuation of salinity and TSS during intensive rainfall on the upper catchment. The strong current from north to the south bending the estuary plume straight to the south. The Dodokan estuary is an open system which has the river bench that is supposed to be absent from any land-use function, but are mostly occupied for human settlement. The domestic waste discharged to the river worsens the quality of riverine water and degrades the estuarine environment. Therefore, its plume water quality is not suggested and is not suitable for mariculture. Based on the water quality map, it is shown that most of the parameters indicate the acceptable range of suitability level criteria for both mari- and aqua-culture in inshore-marine environment. There is no extreme values of parameters that jeopardises those environments. The mining moratorium on the upper catchment assist the coastal lowland environment to selfremediate its water and soil quality. The infrequent rainfall events during the dry season decrease the sediment supply to the estuary and inshore-marine environment thus the water quality is ameliorated compared to the rainy season. Therefore, this suitability level is applicable during the dry season only. 
Figure 4. Sea-water environment suitability map for mari-culture shown by the green shade area.

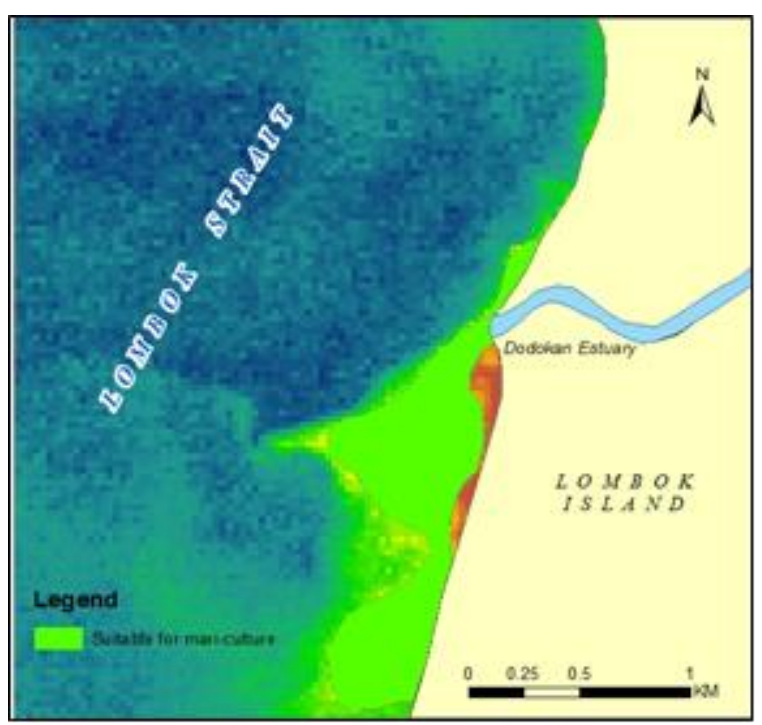

The examination of the remote sensing data and GIS usages in determining water quality

The availability of multi-resolution and multi-temporal satellite imageries have been supporting the needs of researcher in understanding the water quality dynamic processes which are not easy to observe by only using field measurement. Enormous studies on marine and coastal using MSS, Landsat 1-5 to NOAA and MODIS, and other more satellite data, have complement each other in order to achieve better accuracy in mapping the parameters of water quality on the ocean and coastal (Green et al., 2000). In this study, the multi-temporal satellite data that were utilized to recognize the distribution of plume, representing the sediment supply from the Dodokan upper catchment throughout the year. The supplementary spatial modelling generated from spectral transformation and field measurement only used one time acquisition of Landsat 8 satellite imagery which was recorded during the dry seasons. As a result, the ranges of water quality parameters are only available for this seasons only. In fact, the water environment suitability criteria should involve at least one year long data to provide more accurate level of suitability. Nevertheless, since this study focus on how the satellite remote sensing can assist the assessment of water quality environment on a vast area effectively, the detail procedures presented in this paper have sufficiently provided.

The results also show that uses of medium resolution remote sensing data, even though are mostly intensive applied in global and regional scales instead of macro or local, still can overcome the limitation of periodic data, especially in developing country like Indonesia. Selecting appropriate mapping unit to select the most representative samples and size is proven as an effective approach to extract more detail information from remote sensing data. The less intensive field measurement become a beneficiary in part of using the remote sensing spectral transformation. Therefore, the validity of the final maps can be obtained in less cost and time likewise.

Recent studies in developed countries has involved sophisticated instrument including hyperspectral remote sensing to estimate estuarine and coastal water quality (Brando and Dekker, 2003), that enable us to process data using higher spatial resolution and more frequent time acquisition data. This recent technology can derive more data including salinity, TSS, and other type of water pollutants. However, those data are limited, costly and are not always available in Indonesia. Therefore, the results of this current study emphasize that the limited data availability does not hinder the use of remote sensing data for marine and coastal studies in Indonesia, as long as the sampling method chosen are accurate.

It also presents that geographical (GIS) approach can be used to optimize the use of RS data and minimize the error produced from limited data and sampling distributions. The experts who have experience and knowledge on remote sensing and water quality basic concept are certainly needed in utilizing these RS and GIS applications. These expert resources will accentuate the most appropriate method used in developing the model and determine the statistical method to increase the accuracy level of the mapping result.

\section{Conclusion}

Dodokan Estuary, despite its high sedimentation only occurs during the rainy season, has considerably low turbidity during dry season. Due to continuous freshwater discharge to the sea, the salinity around the estuary entrance is close to brackishwater than seawater. Thus, this area is classified as unsuitable for marine biota habitat. However, for general culture system that needs a brackish-water environment, such as tiger shrimp, this source of brackish-water can be managed to supply the water need on the brackishwater ponds. On the other hand, the in-shore marine water quality surrounding the estuary entrance is suitable for mari-cultures, such as: netcage for groupers or other marine fishes. 
This study are also able to show the ability of Remote sensing and GIS in providing SST and chlorophyll-a data using spectral transformation, with the support of field measurement. The synoptic overview of the broader area which is captured spatially (larger area and multi-temporal) enable the user to observe environmental aspects that are not possibly seen in terrestrial survey level. This adequate information will provide more valid information of coastal coastal characteristics as a foundation of coastal and inshore marine sustainable management.

\section{References}

Bird, E.F. and O.T.R. Ongkosongo. 2000. Environmental Change of the Coast of Indonesia. United Nations, University of Tokyo.

Boyd, C.E. 2015. Water quality: an introduction. Springer. Switzerland.

Brando, E.V. and G.A. Dekker. 2003. Satellite Hyperspectral Remote Sensing for Estimating Estuarine and Coastal Water Quality. IEEE Geoscience and Remote Sensing Letters, 41(6) : 1378-1387.

Campbell, G., R.S. Phinn, A.G. Dekker, and E.V. Brando. 2011. Remote sensing of water quality in an Australian tropical freshwater impoundment using matrix inversion and MERIS images. Remote Sensing of Environment, 115 (9) : 2402-2414.

CSIRO Australia. 2003. The Australian AVHRR Data Set at CSIRO/EOC: Origins, Processes, Holdings and Prospects. Earth Observation Centre Report: Australia.

Chander, G.L.B. and J.A. Barsi. 2007. Revised Landsat-5 Thematic Mapper Radiometric Calibration. IEEE Geoscience and Remote Sensing Letters, 4 (3) : 490-494.

Chander, G., B.L. Markham, and D.L. Helder. 2009. Summary of current radiometric calibration coefficients for Landsat MSS, TM, ETM+, and EO-1 ALI sensors. Remote Sensing of Environment, 113 : 893-903.

EPA. 2012. Recreational Water Quality Criteria. Health and Ecological Criteria Division, Office of Science and Technology: United States.

FAO. 2009. Environmental impact assessment and monitoring in aquaculture. FAO Fisheries and Aquaculture Technical Paper, No. 527. Rome. 57 pp.

Green, E.P., A.P. Mumby, J.A. Edwards, and D.C. Clark. 2000. Remote Sensing Handbook for Tropical Coastal Management. United Nations Educational, Scientific and Cultural Organization: Paris.

Hoffmann, A., J. Penner, K. Vohland, W. Cramer, R. Doubleday, K. Henle, and L. Penev.
2014. The need for an integrated biodiversity policy support process-Building the European contribution to a global Biodiversity Observation Network (EU BON). Nature Conservation, 6, 49.

Hutabarat, S. 2000. ProduktivitasPerairandan Plankton.Universitas Diponegoro: Semarang.

Kishino. 1998. In-Water Algorithms for ADEOS/OCTS. Journal of Oceanography, $54: 431$ - 436.

Krisnayanti, B.D., C.W. Anderson, W.H. Utomo, X. Feng, E. Handayanto, N. Mudarisna, and $\mathrm{H}$. Ikram. 2012. Assessment of environmental mercury discharge at a four-year-old artisanal gold mining area on Lombok Island, Indonesia. Journal of Environmental Monitoring, 14 (10) : 2598-2607.

Lung, W.S. 1993. Water quality modelling: application to estuaria. Vol. II CRC Press. Florida.

MFE (Ministry for the Environment). 2003. Keputusan Menteri nomor 111 tahun 2003 tentang Baku Mutu Air Limbah Domestik. Menteri Negara Lingkungan Hidup.

My, H.H.T. and S. Takeda. 2015. Decentralization in Mangrove Restoration: a Critical Analysis-Case study in Central Coast of Vietnam.

Pan, X., G.T.F. Wong, T.-Y. Ho, F.-K. Shiah, and H. Liu. 2013. Remote sensing of picophytoplankton distribution in the northern South China Sea. Remote Sensing of Environment, 128 : 162-175.

Putra, I.B.G. 2007. Kajian DAS Jangkok serta Alternatif Penanganannya. Jurnal Kualitas Air, 8 (2).

Quinn, P. 2014. Catchment systems science and management: from evidence to resilient landscapes. In EGU General Assembly Conference Abstracts, 16, pp. 8117

Rimmer J.C., M.B. Collins, and C.B. Pattiaratchi. 2007. Mapping of water quality in coastal waters using Airborne Thematic Mapper data. International Journal of Remote Sensing, 8 (1) : 85-102.

Siswanto, B., B.D. Krisnayani, W.H. Utomo, C.W.N. Anderson. 2012. Rehabilitation of artisanan gold mining land in West Lombok, Indonesia: Characterization of overburden and the surrounding soil. Journal of Geology and Mining Research, 4(1).

Sabia, R., D. Fernández-Prieto, J. Shutler, C. Donlon, P. Land, and N. Reul. 2015. Remote sensing of surface ocean PH exploiting sea surface salinity satellite observations. In Geoscience and Remote Sensing Symposium (IGARSS), 2015 IEEE International (pp. 106-109). IEEE.

USGS. 2015. Using the USGS Landsat 8 Product. Available at: http://landsat.usgs.gov/ Landsat8_Using_Product.php. 